\title{
Short communication: Predictors of time to dairy calf bucket training
}

\author{
C. Mandel, ${ }^{*}$ A. Adams-Progar, $†$ W. M. Sischo, ${ }^{*}$ and D. A. Moore ${ }^{* 1}$ \\ ${ }^{*}$ Department of Veterinary Clinical Sciences, and \\ †Department of Animal Sciences, Washington State University, Pullman 99164
}

\section{ABSTRACT}

The time required to adequately bucket-train a dairy calf to drink its milk allotment is unknown. Additionally, factors that could predict calves who are slow to learn have not been identified. A prospective observational study was conducted to describe timing of bucket training and possible calf birth and colostrum quality factors that might predict calves requiring extra time to train. On one dairy farm, 1,235 calves were enrolled at birth in a prospective cohort study. Calving ease score, calf presentation at birth, twinning, calf sex, and dam parity were recorded by farm personnel. An as-fed colostrum sample for each calf was collected and evaluated for total solids, total plate bacterial count, and coliform bacterial count. Calf serum total protein values were obtained by d 2 to 3 of life. Calves were observed before the morning milk feeding for attitude/posture, and after feeding for assistance needed to drink milk from their bucket. Attitude/posture was significantly associated with whether a calf required assistance or not. Almost $60 \%(\mathrm{n}=724)$ of calves consumed their morning milk allotment (2 L) after d 3 of life without assistance. Significant factors associated with the odds of requiring assistance with drinking after $3 \mathrm{~d}$ of age included calf sex, being born a twin, and the week the calf was enrolled. Knowing how long it takes to train a calf to drink from a bucket could be useful in allocating the time or labor required to successfully train calves.

Key words: pre-weaned calf, bucket training, neonatal risk

\section{Short Communication}

Pre-weaned dairy calves in individual housing may be fed milk or milk replacer by bottle or bucket. Bucket feeding is relatively common in North America. In a recent US study of dairy management practices, $72 \%$ of dairy operations used a bucket at least some time in

Received May 22, 2017.

Accepted August 11, 2017.

${ }^{1}$ Corresponding author: damoore@vetmed.wsu.edu the pre-weaning period and almost $60 \%$ of pre-weaned heifer calves were fed by bucket (USDA, 2016). In Quebec, Canada, bucket feeding was more common with about $92 \%$ of dairy farms feeding milk or milk replacer from a bucket (Vasseur et al., 2010). Some famers may start calves on bottles and then train them to buckets. Providing a teat to bucket-fed calves, either through a nipple bucket or a dry teat, would allow them to fulfill their need to suckle (de Passillé, 2001), but some disadvantages are possible. Buckets are considered easier to clean than nipple buckets or bottles (Quigley, 1997). The practice of bucket training is described as caretakers placing their fingers in the calf's mouth and leading them to the bucket so they can learn to drink milk (Pate, 2006). Despite this model of training, no current literature is available that describes how much time a normal, healthy calf requires to be trained to drink from a bucket. The only information currently available on bucket training is from a non-peer-reviewed source and suggests that some calves learn instantly, whereas others take "a few days" (Thornsberry, 2012). On large dairy farms or calf ranches, having large numbers of calves to train daily could tax labor. It is unknown what might influence the time to successful bucket training. If known, risks could be mitigated to reduce overall time to train calves.

Calves may be affected physiologically at birth if they are involved in a dystocia resulting in low calf vitality (Murray and Leslie, 2013). Calves assisted at birth were less likely to stand and walk within the first $3 \mathrm{~h}$ and laid on their flanks longer than nonassisted calves (Barrier et al., 2012). Reasons for low vitality at birth include a variety of factors such as neonatal hypoxia and acidosis (Szenci et al., 1988), physical trauma and fractures (Ferguson, 1994), and aspiration pneumonia (Lopez and Bildfell, 1992). Neonatal hypoxia may have short-term effects such as weakness in the newborn (Kasaria, 1994) and affect absorption of colostral antibodies (Besser et al., 1990). The consequences of dystocia may have longer term effects on morbidity and mortality in the pre-weaning period (Lombard et al., 2007). Reasons for dystocia include fetal-maternal size mismatch, often found in first calf heifers, body 
condition of the dam, twinning, and calf sex (Lombard et al., 2007), and calf birth weight was associated with pre-weaning mortality on a calf ranch (Moore et al., 2002). Because dystocia and other factors have effects on calf vitality and health, effects on neonatal appetite within the first week of life, or ability to learn to drink from a bucket, are possible. The objectives of this study were to describe the time to successful bucket training and identify factors that might influence the training period.

A prospective cohort study was conducted on a large commercial Holstein dairy farm with calves enrolled at birth from May 5, 2016, to July 27, 2016, as part of a broader, multi-farm study investigating perinatal risks for morbidity. Farm personnel were asked to record calving ease score $(1=$ normal delivery, $2=$ some assistance, or 3 = difficult birth, "hard pull"), whether the calf was a twin, calf sex, and dam information (primiparous or multiparous) at birth. Farm personnel had a second system they used to record calf birth presentation (coming forward, backward, or backward and pulled). Calf heart girth measurement after birth was collected by study personnel using a centimeter measuring tape.

Each calf received $4 \mathrm{~L}$ of colostrum by esophageal feeder within $2 \mathrm{~h}$ of birth and then $2 \mathrm{~L} 2 \mathrm{~h}$ later, also by esophageal feeder. A sample of the first as-fed colostrum was retained for each calf and placed into a 50-mL tube on ice until received at the laboratory. The sample was tested for total aerobic bacterial count, total coliform count, and Brix percent using a digital refractometer (Palm Abbe, Misco, Solon, OH) by research technicians. For total bacterial count, a set of six 1:5 dilutions were made with $750 \mu \mathrm{L}$ of colostrum, used to plate on Petrifilm (Petrifilm Aerobic Count Plate, $3 \mathrm{M}$, St. Paul, MN), and incubated at $30^{\circ} \mathrm{C}$ for $48 \mathrm{~h}$. For coliform bacterial counts, a series of 5 1:5 dilutions were created with $750 \mu \mathrm{L}$ plated onto Petrifilm (Petrifilm Coliform Count Plates, 3M) and incubated at $35^{\circ} \mathrm{C}$ for $24 \mathrm{~h}$. All colony counts were done by visual observations and recorded as raw counts and as $\log _{10}$ colony-forming units.

Within the first $24 \mathrm{~h}$ of life, calves were removed from the cows and placed into wooden hutches with about $3 \mathrm{~m}^{2}$ for each calf. Each hutch contained 2 sideby-side pens that allowed for nose-to-nose contact with adjacent calves. Serum total protein was tested by farm personnel on d 2 or 3 of life using an optical refractometer. Starting on the second day of life, calves were fed $2 \mathrm{~L}$ of whole unpasteurized milk by bucket twice daily. Observations for the need for assistance to drink from the bucket were made immediately after the bucket was filled. Initially, the bucket was placed outside the hutch so calves had to extend their heads to gain access. If they did not consume all the milk immediately, the bucket was moved into the hutch (recorded as assisted feeding). Assistance at feeding included active training by farm personnel followed by tube feeding. Active training included holding the bucket in front of the calf, placing milk in the calf's mouth to stimulate sucking, and leading the calf to the milk with a hand. If the calf refused to drink from the bucket, they were tube-fed the remainder of their milk. Calves slow to eat but completing their milk allotment by themselves were classified as not assisted. Four farm personnel were responsible for feeding and assistance with bucket training, including the calf manager. Variability in training techniques were not evaluated, but all personnel were trained by the calf manager and were experienced calf feeders.

Observations were made daily for each study calf for $21 \mathrm{~d}$ by 6 trained research technicians/investigators before (attitude/posture) and after (assistance with feeding, tubing, moving bucket, bottle feeding) the morning milk feeding. A set of posture observations, adapted from an attitude scoring system described by Fecteau et al. (1997), were used to evaluate a calf's attitude before feeding. The observations were categorized as alert (i.e., interested and responsive to their surroundings) and standing, alert and sternal, depressed [i.e., slow to respond to their surroundings (standing or sternal)], or nonresponsive. All staff involved in scoring were trained as a group and evaluated for agreement by a single investigator. No formal measure of agreement was determined as a high proportion of calves were considered alert, and inherently, agreement would be good.

Descriptive statistics were done in a spreadsheet program (Excel, Microsoft Corp., Redmond, WA), Epi Info (Epi Info V. 7.1.4.0, Centers for Disease Control and Prevention, Atlanta, GA), and R (R Project and Quick-R, http://www.statmethods.net/advstats/glm .html). Bivariate and logistic regression analyses were done using $\mathrm{R}$ and Epi Info. For the logistic regression analysis, a backward, stepwise reduction of variables with initial bivariate associations $(P<0.20)$ was instituted to establish the best generalized linear model. Total serum protein values were assessed using a cut point where the upper range was greater than or equal to $5.5 \mathrm{~g} / \mathrm{dL}$ (Deelen et al., 2014). Dehydration at time of the blood draw was not evaluated.

A total of 1,235 calves, including both bull and heifer calves, were enrolled over a 12 -wk period. About half the calves were heifers $(51.4 \%)$ and born to a multiparous cow (56.2\%). About $10 \%$ were born as a twin, and most presented forward (94\%) with a calving ease score of 1 (Table 1 ). Heart girth at birth averaged 78.2 
Table 1. Bivariate analyses for the association of dam, calf, and week of enrollment risk factors for being assisted with bucket milk feeding after d 3 of life on one dairy farm for 1,235 calves enrolled at birth

\begin{tabular}{|c|c|c|c|c|}
\hline Item & Category $(\mathrm{N})$ & $\begin{array}{c}\text { Not assisted } \\
(\%)\end{array}$ & $\begin{array}{c}\text { Assisted } \\
(\%)\end{array}$ & $P$-value \\
\hline \multirow[t]{2}{*}{ Sex } & Bull (597) & 54 & 46 & \\
\hline & Heifer (632) & 63.9 & 36.1 & 0.0005 \\
\hline \multirow[t]{2}{*}{ Dam } & Heifer (536) & 56.9 & 43.1 & \\
\hline & Cow (688) & 60.9 & 39.1 & 0.15 \\
\hline \multirow[t]{2}{*}{ Twin } & No $(1,120)$ & 60.2 & 39.8 & \\
\hline & Yes $(115)$ & 48.2 & 51.8 & 0.01 \\
\hline \multirow[t]{3}{*}{ Calf orientation at birth } & Backward, pulled (27) & 44 & 56 & \\
\hline & Backward (51) & 44 & 56 & \\
\hline & Forward $(1,157)$ & 60 & 40 & 0.02 \\
\hline \multirow[t]{3}{*}{ Calving score } & $1(1,102)$ & 59.4 & 40.6 & \\
\hline & $2(81)$ & 57.5 & 42.5 & \\
\hline & $3(46)$ & 53.3 & 46.7 & 0.68 \\
\hline \multirow[t]{12}{*}{ Week of enrollment } & 1: May 5-11 (54) & 40.74 & 59.26 & \\
\hline & 2: May 12-18 (79) & 43.04 & 56.96 & \\
\hline & 3: May 19-25 (104) & 48.08 & 51.92 & \\
\hline & 4: May 26-June 1 (108) & 37.04 & 62.96 & \\
\hline & 5: June $2-8(110)$ & 54.55 & 45.45 & \\
\hline & 6: June 9-15 (97) & 59.79 & 40.21 & \\
\hline & 7: June $16-22(101)$ & 59.41 & 40.59 & \\
\hline & 8: June 23-29 (111) & 56.76 & 43.24 & \\
\hline & 9: June 30-July 6 (112) & 75.00 & 25.00 & \\
\hline & 10: July $7-13$ (101) & 68.32 & 31.68 & \\
\hline & 11: July 14-20 (106) & 78.30 & 21.70 & \\
\hline & 12: July $21-27$ (142) & 71.13 & 28.87 & $<0.001$ \\
\hline
\end{tabular}

cm (range $64.5-89.0 \mathrm{~cm}$ ) and $27.9 \%$ of 1,208 calves evaluated had total serum protein values $<5.5 \mathrm{~g} / \mathrm{dL}$. Considerable variation was present in colostrum quality measurements. The colostrum Brix refractometer readings ranged from 13.8 to $33.2 \%$. Colostrum total plate count ranged from no growth to $8.6 \log _{10} \mathrm{cfu} / \mathrm{mL}$ and colostrum total coliform count ranged from no growth to $8.23 \log _{10} \mathrm{cfu} / \mathrm{mL}$. Thirty-nine calves $(3.2 \%)$ died during the first $21 \mathrm{~d}$ of life.

From bivariate analyses of potential risk factors with each other, some significant associations were found. Multiparous cows gave birth to calves with larger heart girths, on average, compared with primiparous animals (means $=78.7 \pm 4.5,77.4 \pm 3.1 \mathrm{~cm}$, respectively; $P$ $<0.0001)$. Bull calves were larger than heifer calves $($ means $=78.7 \pm 4.6,77.6 \pm 3.2 \mathrm{~cm}$, respectively; $P$ $<0.0001$ ). Twins were smaller than singletons (means $=75.2 \pm 3.7,78.4 \pm 3.9 \mathrm{~cm}$, respectively; $P<0.0001)$ and the largest calves were more likely to be born in the first week of enrollment $(P=0.01)$. Although statistically significant relationships were present between total serum protein and heart girth, $\log _{10}$ of the coliform count, and $\log _{10}$ of the total plate count $(P<0.001)$, these 3 factors did not explain much of the variation in calf total serum protein $\left(\mathrm{R}^{2}<0.05\right)$. Calves born in the last week of enrollment had the highest serum total protein, on average $(P<0.0001)$. Calf presentation at birth, as recorded by farm personnel, was associated with calving ease score, dam, and calf sex $(P<0.01)$, and a tendency was observed for more twin births to be associated with calves who presented backward, were pulled, or both $(P=0.07)$.

Attitude/posture observations before the morning feeding were summarized for d 2 to 7 of life. On $24.8 \%$ of the 7,203 calf-days of observation, calves required assistance with their milk feeding. Most of that assistance (did not finish their morning milk allotment) was in the first week of life (Figure 1). Calves that appeared alert but were sternal were 2.43 times more likely to require assistance with feeding compared with calves that were alert and standing before the morning feeding (95\% CI $2.23,2.65)$. Calves that appeared depressed before the morning feeding were 4 times more likely to be assisted with feeding compared with calves that were alert and standing and 1.64 times more likely to be assisted compared with calves that were alert but sternal (95\% CI $3.38,4.72 ; 1.4,1.92$, respectively).

Almost $60 \%(\mathrm{n}=724)$ of calves consumed their morning milk allotment (2 L) after d 3 of life without assistance (Figure 1) with an average of $3.4 \mathrm{~d}$ (SD $=0.87$ ). Based on these data, d 3 was chosen as the "normal" time to complete bucket training and time to successful bucket feeding was dichotomized into $\leq 3$ and $>3 \mathrm{~d}$. Ten calves died before $3 \mathrm{~d}$ of age and were excluded from analyses. Bivariate analyses resulted in some significant associations between assistance after 3 $\mathrm{d}$ and several potential risks (Table 1 ). The $\log _{10}$ of the total colostrum bacterial count $(P=0.01)$, total serum 
Table 2. Logistic regression results for factors associated with the probability of a calf requiring assistance with drinking milk from a bucket after d 3 of life

\begin{tabular}{lcccrc}
\hline Term & Odds ratio & \multicolumn{2}{c}{$95 \%$ CI } & Coefficient & $P$-value \\
\hline Dam (heifer vs. cow) & 1.26 & 0.98 & 1.61 & 0.229 & 0.07 \\
Calf sex (heifer vs. bull) & 0.66 & 0.51 & 0.84 & -0.414 & $<0.001$ \\
Twin (yes vs. no) & 1.72 & 1.13 & 2.65 & 0.548 & 0.01 \\
Week of enrollment & & & & & \\
1 & Reference & & & & \\
2 & 0.91 & 0.45 & 1.86 & -0.077 & 0.83 \\
3 & 0.73 & 0.37 & 1.43 & -0.316 & 0.36 \\
4 & 1.18 & 0.60 & 2.32 & 0.164 & 0.63 \\
5 & 0.54 & 0.28 & 1.06 & -0.609 & 0.07 \\
6 & 0.47 & 0.24 & 0.93 & -0.763 & 0.03 \\
7 & 0.47 & 0.24 & 0.94 & -0.745 & 0.03 \\
8 & 0.51 & 0.26 & 0.99 & -0.681 & 0.05 \\
9 & 0.23 & 0.12 & 0.47 & -1.453 & $<0.001$ \\
10 & 0.31 & 0.16 & 0.63 & -1.168 & 0.001 \\
11 & 0.19 & 0.09 & 0.38 & -1.680 & $<0.001$ \\
12 & 0.28 & 0.15 & 0.54 & -1.270 & $<0.001$ \\
\hline
\end{tabular}

protein $(P=0.15)$, presentation of the calf at birth (forward, backward, or backward and pulled), calving ease score, dam (heifer vs. cow), calf sex, being a twin, and week of enrollment were included in the model for the probability of assistance after $3 \mathrm{~d}(P<0.20$; Table 1).

The final logistic regression model for the probability of requiring assistance at the morning feeding after $\mathrm{d}$ 3 of life included dam, calf sex, being born a twin, and week of enrollment (Table 2). Calves born to heifers had a tendency to be more likely to require assistance with drinking compared with calves born to cows $(P$ $=0.07$ ). Controlling for dam, week of enrollment, and being a twin, heifer calves were 1.5 times less likely to require assistance after d 3 compared with bull calves $(P=0.002)$. Twin calves had almost twice the odds of requiring feeding assistance after d 3 of life compared with singletons $(P=0.01)$. Each week after the fifth week of enrollment, calves were less likely to require feeding assistance after d 3 compared with those in the first week of enrollment (all $P<0.05$ ).

This is the first description of bucket training and factors associated with assistance with milk feeding. Training to drink from a bucket took calves, on average, over $3 \mathrm{~d}$. The ability to use an automated milk feeder required assistance for all calves on d 1 (after 5-6 d of age when moved to the feeder) and only $6.5 \%$ of calves required assistance by d 6 (Fujiwara et al., 2014). A wide variation was observed among calves in that study, from about $5 \mathrm{~h}$ to almost $10 \mathrm{~d}$ of assistance; however, those calves were not introduced to the feeder until about $6 \mathrm{~d}$ of age. About $27 \%$ of these older calves

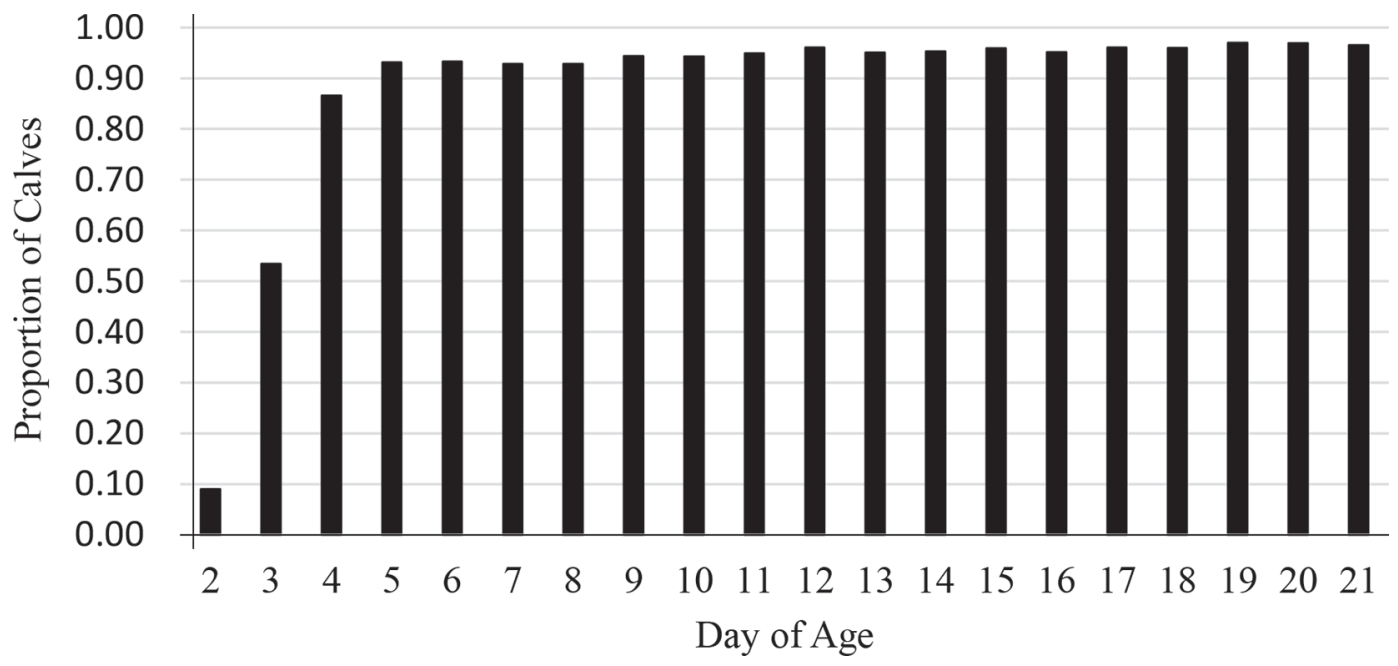

Figure 1. Proportion of calves from a 1,235 dairy calf cohort that consumed their entire morning bucket liquid feed allotment (2 L) by day of age. 
were able to drink without assistance within $24 \mathrm{~h}$ of introduction to the group pen with the automated feeder and most took more than $3 \mathrm{~d}$. Similarly aged calves that were limit-fed took about 1 to $4 \mathrm{~d}$ of assistance to learn to drink from an automated feeder (Jensen, 2007). Despite feeding methods, it appears that labor is required for several days, on average, to train calves to drink their entire milk allotment.

Although the factors we identified as possible risks for slow bucket training are not easily mitigated, we did uncover some useful information. Observations commonly made about calves, attitude/posture, and completion of their milk were highly correlated in our study during the first week of life. The attitude/ posture observations appear to be appropriate monitors to identify potential health problems in neonatal calves that might also diminish milk consumption. Feed reduction is a hallmark of bovine respiratory disease detection in older calves (Toaff-Rosenstein et al., 2016). We did not expect to see that a calf that looked alert but was sternal before the morning feeding would be more likely to require assistance to drink. Borderas et al. (2009) found that with automated feeding systems for calves $>4 \mathrm{~d}$ of age, those limit-fed $4 \mathrm{~L}$ per day only decreased their duration of visits to the feeder but not their total feed consumption when ill, in contrast to calves allowed $12 \mathrm{~L}$ of milk. Even with limit-fed calves as in our study, subtle differences in behavior (attitude/ posture), if measured at the appropriate time, could be an indicator of a calf requiring additional attention. Because limit-fed calves would likely have more motivation to drink and stand longer than ad libitum fed calves (De Paula Vieira et al., 2007), the fact that calves were not standing just before the morning feeding in our study (alert but sternal) appears to indicate something different about those calves.

Bull calves, twins, and birth week were associated with assistance required to drink from a bucket after 3 $\mathrm{d}$ of age. Although calving ease score was not significant in the final model, it was associated with calf sex and twin birth in the bivariate analysis. Because the variables were correlated, specific calf information was included in the model. It is possible that inaccurate recording of birth events resulted in misclassification. Nondifferential misclassification of the exposure (calving ease score or calf orientation) would bias results toward no statistical difference or relationship between variables (Rothman and Greenland, 1998). Week of enrollment was important in this study and compared with the first week, calves enrolled after June 8, 2016, were 2 to 5 times less likely to require assistance with feeding. It is possible that management or environmental conditions accounted for these differences. Ambient temperatures increased from 25.5 to $35.5^{\circ} \mathrm{C}$ over the course of calf enrollment. As temperatures rose at the end of the enrollment period, calves may have been more prone to dehydration and thirst, increasing their motivation to drink and decreasing their requirement for assistance. Bucket training calves requires considerable time and labor. Understanding time requirements and risks could help dairy farmers match calf needs to labor requirements to ensure calves are able to fully consume their allotment of liquid feed, thereby promoting calf health and growth.

\section{ACKNOWLEDGMENTS}

The authors thank the dairy farm owner and employees. This work was supported by USDA National Institute of Food and Agriculture (Washington, DC) Grant No. 2015-68003-22998. The project was reviewed and approved by the Institutional Animal Care and Use Committee at Washington State University, \#04497-002.

\section{REFERENCES}

Barrier, A. C., E. Ruelle, M. J. Haskell, and C. M. Dwyer. 2012. Effect of a difficult calving on the vigour of the calf, the onset of maternal behaviour, and some behavioural indicators of pain in the dam. Prev. Vet. Med. 103:248-256. https://doi.org/10.1016/j .prevetmed.2011.09.001.

Besser, T. E., O. Szenci, and C. C. Gay. 1990. Decreased colostral immunoglobulin absorption in calves with postnatal respiratory acidosis. J. Am. Vet. Med. Assoc. 196:1239-1243.

Borderas, T. F., J. Rushen, M. A. G. von Keyserlingk, and A. M. B. de Passille. 2009. Automated measurement of changes in feeding behavior of milk-fed calves associated with illness. J. Dairy Sci. 92:4549-4554. https://doi.org/10.3168/jds.2009-2109.

de Passillé, A. M. 2001. Sucking motivation and related problems in calves. Appl. Anim. Behav. Sci. 72:175-187. https://doi.org/10 .1016/j.applanim.2007.03.006.

De Paula Vieira, A., V. Guesdon, A. M. Passillé, M. A. G. von Keyserlingk, and D. M. Weary. 2007. Behavioural indicators of hunger in dairy calves. Appl. Anim. Behav. Sci. 109:180-189. https://doi .org/10.1016/j.applanim.2007.03.006.

Deelen, S. M., T. L. Ollivett, D. M. Haines, and K. E. Leslie. 2014 Evaluation of a Brix refractometer to estimate serum immunoglobulin $\mathrm{G}$ concentration in neonatal dairy calves. J. Dairy Sci. 97:3838-3844. https://doi.org/10.3168/jds.2014-7939.

Fecteau, G., J. Paré, D. C. Van Metre, B. P. Smith, C. A. Holmberg, W. Guterbock, and S. Jang. 1997. Use of a clinical sepsis score for predicting bacteremia in neonatal dairy calves on a calf rearing farm. Can. Vet. J. 38:101-104.

Ferguson, J. G. 1994. Femoral fractures in the newborn calf: Biomechanics and etiological considerations for practitioners. Can. Vet. J. 35:626-630.

Fujiwara, M., J. Rushen, and A. M. Passillé. 2014. Dairy calves' adaptation to group housing with automated feeders. Appl. Anim. Behav. Sci. 158:1-7. https://doi.org/10.1016/j.applanim.2014.06.011.

Jensen, M. B. 2007. Age at introduction to the group affects dairy calves' use of a computer-controlled milk feeder. Appl. Anim. Behav. Sci. 107:22-31. https://doi.org/10.1016/j.applanim.2006.09 .017 .

Kasaria, T. R. 1994. Weakness in the newborn calf. Vet. Clin. North Am. Food Anim. Pract. 10:167-180. http://dx.doi.org/https://doi .org/10.1016/S0749-0720(15)30596-X. 
Lombard, J. E., F. B. Garry, S. M. Tomlinson, and L. P. Garber. 2007. Impacts of dystocia on health and survival of dairy calves. J. Dairy Sci. 90:1751-1760. https://doi.org/10.3168/jds.2006-295.

Lopez, A., and R. Bildfell. 1992. Pulmonary inflammation associated with aspirated meconium and epithelial cells in calves. Vet. Pathol. $29: 104-111$.

Moore, D. A., W. M. Sischo, D. M. Festa, J. P. Reynolds, E. R. Atwill, and C. A. Holmberg. 2002. Influence of arrival weight, season and calf supplier on survival of Holstein beef calves on a calf ranch in California, USA. Prev. Vet. Med. 53:103-115.

Murray, C. F., and K. E. Leslie. 2013. Newborn calf vitality: Risk factors, characteristics, assessment, resulting outcomes and strategies for improvement. Vet. J. 198:322-328. https://doi.org/10.1016/j .tvjl.2013.06.007.

Pate, R. N. 2006. Raising a bucket calf. Utah State University Cooperative Extension. 4H/GBB/2006-01pr. Accessed Nov. 10, 2016 http://extension.usu.edu/files/publications/publication/4H_GBB 2006-01.pdf

Quigley, J. D. 1997. Raising replacement heifers from birth to weaning. Proc. 15th Western Canadian Dairy Seminar. University of Alberta. Accessed Jul. 3, 2017. https://wcds.ualberta.ca/Portals/ 138/Documents/Archive/1997/ch21-97.htm.
Rothman, K. J., and S. Greenland. 1998. Chapter 8-Precision and validity in epidemiologic studies. Pages $115-134$ in Modern Epidemiology. Lippincott-Raven Publ., Philadelphia, PA.

Szenci, O., M. A. Taverne, S. Bakonyi, and A. Erdodi. 1988. Comparison between pre- and postnatal acid-base status of calves and their perinatal mortality. Vet. Q. 10:140-144. https://doi.org/10.1080/ 01652176.1988 .9694161$.

Thornsberry, R. M. 2012. Are bottles or buckets best for feeding calves? Feedstuffs. 84. Accessed Nov. 10, 2016. http://www .feedstuffs.com/story-are-bottles-or-buckets-best-for-feeding-calves $-54-91609$.

Toaff-Rosenstein, R. L., L. J. Gershwin, and C. B. Tucker. 2016. Fever, feeding, and grooming behavior around peak clinical signs in bovine respiratory disease. J. Anim. Sci. 94:3918-3932. https://doi .org/10.2527/jas.2016-0346.

USDA. 2016. Dairy 2014, Dairy cattle management practices in the United States, 2014. Pages 132-133. USDA-APHIS-VS-CEAHNAHMS. Fort Collins, CO. \#692.0216.

Vasseur, E., F. Borderas, R. I. Cue, D. Lefebvre, D. Pellerin, J. Rushen, K. M. Wade, and A. M. Passillé. 2010. A survey of dairy calf management practices in Canada that affect animal welfare. J. Dairy Sci. 93:1307-1315. https://doi.org/10.3168/jds.2009-2429. 